... all of this pales into insignificance when

compared with the fairly mind-blowing

realisation that after decades of dissatisfaction

the profession has, at last, the option to change

the system ...

\title{
Change is, at last, an option
}

We are told that the current time in dentistry will see the greatest changes since the inception of the NHS, that it will affect dentists and patients in many ways, that much of what will happen is still uncertain and that it can be seen as a threat or an opportunity (depending on your point of view). From my own perception, listening to dentists and reading much of the comment in various publications, there is a general awareness that significant change is coming, but many people seem confused by it all and as such feel unhappy, uncertain and definitely threatened. Hence this Special Issue on Options For Change.

Options for Change (or 04C as it is sometimes called) was published in August 2002 amidst a plethora of other changes . The existing system of healthcare within the NHS, especially in the General Dental Services (GDS) has been with us since 1948 and was not just creaking at the edges, it was splitting wide open. Yet, despite the fact that people have been asking for a better system than the existing GDS fee scale since I qualified (in 1967) it seems that the fact it is upon us at last is causing more concern than jubilation. This is natural because the unknown is always more worrying than the known (however bad the known is perceived to be). Yet I do wish that sometimes people would remember that the profession has been asking for a better system than the existing GDS system for a long time.

of course the astute readers will have realised that the key word in my last sentence is 'better'. How do we know the new system will be better than the existing one? The conspiracy theorists tend to believe that any new system has been devised as some kind of plot to 'cheat' dentists even more than the existing system. Many others seem to assume that the new system must be worked out in fine detail before they can 'sign up' to it, forgetting that life is never like that. Perhaps the majority are still wondering what has happened, or in worse cases do not even realise something is going to happen. Whatever there is still a lot of confusion about what is to come, how it will affect people (dentists, dental team members and patients) and what they should be doing about it.

Hence this Special Issue of the $B D J$, which may not provide all the answers but does provide information to help people understand the background and the current position.

I chose 04C (Options for Change) as the focus of the issue because not only does this report encapsulate the philosophy behind the changes, but more importantly demonstrates that the decisions that will mould the future are coming from both the profession and the Department of Health. Thus we will have a say in our own future, (despite the fact that some people will never believe this) and the report itself is quite clear and helps form a sound structure for the negotiations that are currently taking place.

04C really opens the way for consideration of a new structure for the provision of oral health care within the NHS, which will be locally negotiated by primary care trusts (PCTs) and will enable different methods of implementation and remuneration throughout England (although the other countries within the UK will be watching). Instead of imposing a new structure on everyone (as happened in the past) this time we are seeing research into different ways of providing dental care and agreeing remuneration in the PDS pilots and the $04 \mathrm{C}$ field sites (both these are simply groups of people trying different things and reporting on them). Some of these reports are published in this issue of the $B D J$ and make interesting reading for those who would like to get a clearer idea of how the future may look.

Whether you think we are entering a genuinely 'brave' new world or simply swapping one repressive system for another - you need to realise that things are going to change and that the more the profession inputs into these changes the better the future is likely to be. This is not an over-optimistic 'rose-coloured' view - it is basic common sense. But all of this pales into insignificance when compared with the fairly mindblowing realisation that after decades of dissatisfaction the profession has, at last, the option to change the system and to play a part in the direction of that change.

For that we have to thank Options For Change.

Mike Grace, Editor m.grace@bda.org doi:10.1038sj.bdj.4810775 